\title{
SDHA NM_004168.3:c.1660C>T
}

National Cancer Institute

\section{Source}

National Cancer Institute. SDHA NM 004168.3:C.1660C>T. NCI Thesaurus. Code C126831.

A nucleotide substitution at position 1660 of the coding sequence of the SDHA gene where cytosine has been mutated to thymine. 